\title{
Churn Management in Sri Lankan Mobile Market
}

\author{
A. A. R. E. Adikari, S. U. Rabel, and K. Samarasinghe
}

Abstract: Churn is a measure of the number of subscribers who leave or switch to another carrier's service. The frequent migration of customers is in a way a threat to mobile operators as the expense on customer acquisition is greater than retention. On the other hand, for any operator it is difficult to maintain a steady growth in the market without maintaining the existing customers. Due to profound competition, controlling churn rate is becoming a challenge to Mobile Operators and identifying reasons for Churn is an even greater challenge as it is highly dependent on the values, culture, attitudes and perception of the different segments.

The main causes for retention or churn from one network in Sri Lankan context (for different segments) are identified by a questionnaire evaluated across various demographic factors (Age, Education level, Monthly Income, Gender). The questionnaire was distributed among 400 mobile subscribers and received 305 responses which were used in the analysis set out in the paper to follow. Strategies that can be used to minimize churn rate is identified based on the feed back received in the questionnaire and by looking at best practices available in the region. Finally, Researchers developed a model to prioritize the influencing factors (Tariff, Coverage, Brand, VAS, and QOS) for overall customer satisfaction of Sri Lankan Mobile customers and checked whether there is any relationship with demographic factors and influencing factors for churn. In addition to that, researchers have suggested strategies that should be adopted by Sri Lankan mobile operators to minimize churn.

Keywords: Churn, Mobile Communication

\section{Introduction}

\subsection{Sri Lankan Mobile Industries}

During the last few years, Sri Lankan Telecommunication industry (especially mobile Industry) has shown a significant growth compared to other Industries. According to statistics in the 1st Quarter 2007, Sri Lanka has a Tele density of $40 \%$, distributed as follows [1].

\section{Table 1: Statistics of the Telecommunication} Sector as end of 1st Quarter 2007

\begin{tabular}{|l|l|l|}
\hline Number of Telephones & Cellular & $5,958,685$ \\
\hline Number of Telephone & Fixed & $2,086,774$ \\
\hline Tele-density & Fixed & $10 \%$ \\
\hline Tele-density & Cellular & $30 \%$ \\
\hline Tele-density & Total & $40 \%$ \\
\hline
\end{tabular}

After 2002, the growth rate of Sri Lankan Mobile market changed exponentially and that variation can be clearly observed through the following graph.[1]

In relation to the concept of product life cycle, it is evident that the mobile industry is reaching its maturity stage.

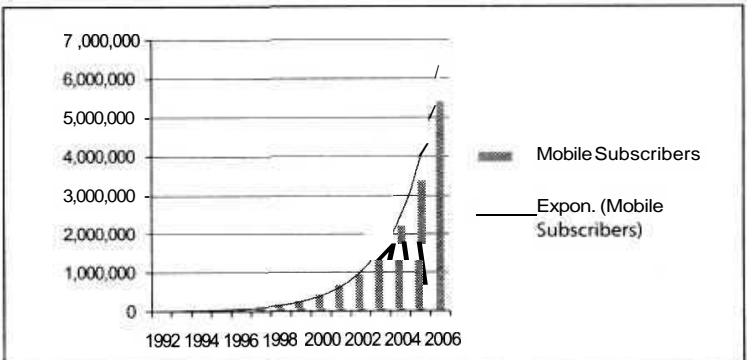

Figure 1: Growth in Mobile market in SriLanka

In this regard it is of paramount importance that the operators manage churn (i.e. subscribers leaving the network) as churn management helps retain market share. The expansion in the mobile market has given greater choice to mobile subscribers creating opportunity to switch from one operator to another if not satisfied with the current service provider. The frequent migration of customers is in a way a threat to mobile operators as the expense on customer acquisition is greater than retention.

A.A.R.E.Adikari, B.Sc Eng.(Peradeniya), AIESL, MIEEEAssistant Manager-ISAnalytics, Dialog Telekom PLC

Eng. A.T.L.K. Samarasinghe, B.Sc Eng.(Moratuwa), M.B.A(Sri ]), C.Eng, MIE(SL), Head of Department, Department of Electronic and Telecommunication, University of Moratuwa

S.U.Rabel, B.Sc Eng.(Moratuwa), MBA, CIMA, Senior Manager Group IS Strategy and Business Intelligence, Dialog Telekom PLC 
On the other hand, for any operator it is difficult to maintain a steady growth in the market without maintaining the existing customer. The present Sri Lankan mobile industry is extremely dynamic, with new services, technologies, and carriers constantly altering the landscape. High churn rates impact as bad debts which cost over US\$6 billion each year to Asian mobile operators. Particularly, the two biggest markets in Asia - China and India - have churn rates that are significantly higher than the regional average. [2]

\section{Literature Review}

\subsection{Definition of Churn}

Churn is a measure of the number of subscribers who leave or switch to another carrier's service. In other words churn is the gross rate of customer loss during a given period. Churn Rate can be described as follows. [5]

Monthly Churn Rate $=(\mathrm{Co}+\mathrm{A} 1-\mathrm{C} 1) / \mathrm{Co}$

Where

Co $=$ Number of customers at the start of the month

$\mathrm{Al}=$ Gross addition or reconnection during the month

$\mathrm{Cl}=$ Number of customers at the end of the month

A High churn rate is a significant issue for a operator as it leads to

- Rising customer acquisition costs

- Lower average monthly revenue

- Increased deactivation costs

- Higher pressure to acquire new customers

- Increased risk

- Loss of brand value

- Loss of opportunity to sell related products and value added services

- Underutilized resources

Churn is two fold comprising voluntary churn $\&$ involuntary churn. [5] Voluntary churn refers to the subscriber leaving the network willfully due to reasons such as incorrect perception of Price, Quality, Coverage, Customer Service, Brand, Technology etc while Involuntary churn refers to the operator disconnecting the line due to Credit issues, Fraud or Non Usage, etc. [3]

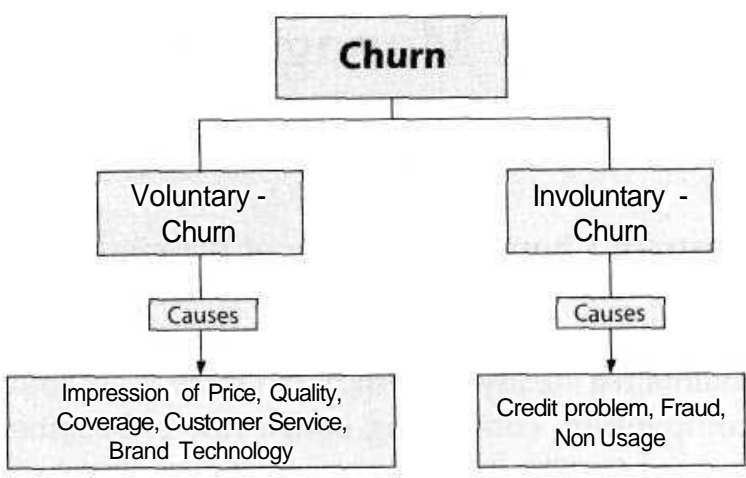

Figure 2: Possible causes of Churn

\subsection{How to Manage Churn}

For churn management, mobile operator has to improve their existing processes in acquisition, activation, controlling etc as otherwise unnecessary delays may occur. Following areas should be addressed to manage churn effectively. [6]

- Customer information management

- Customer strategy development

- Value proposition creation

- Customer operations

- Customer contact management

It is vital that the operators understand customer behavior based on analysis of customer records and identify strategies to minimize the churn of customers based on their past behavior [5]

Key strategies include:

- Incentives and tariff bundles which target the most profitable customers

- Loyalty schemes which are appropriate to the value of the business saved

- Acquisition strategies which attract the right type of customer, reducing fraud and bad debt

- Proactive customer service including the offer the best-fit tariff plan to the customer

- A commitment to quality in all aspects of the business.

- Geographical discounts

- Improvement for existing customers based on network stay 


\section{Methodology}

\subsection{Sample Selection}

Target Population $=$ Total mobile subscribers in the country (6 million as at 1st quarter of 2007)

C'alculating the sample size

Where

Sample size is calculated using the equations given below.

$$
S=\frac{s s}{1+\frac{(s s-1)}{p o p}}
$$

Where;

$$
s s=\frac{Z^{2} p(1-p)}{c^{2}}
$$

$\%$ is the $\mathrm{Z}$ value for the relevant Confidence Level (CL)

$\mathrm{p}$ is 0.5 for calculating the sample size

Cis the Confidence Interval (CI)

pop is the population size

Table 2: Calculation of sample size Survey

Results

\begin{tabular}{|l|l|l|l|l|l|l|}
\hline & CI & 0.05 & 0.1 & 0.15 & 0.2 & 0.25 \\
\cline { 1 - 4 } CL & $Z$ & & & & & \\
\hline 95 & 1.96 & 385 & 97 & 43 & 25 & 16 \\
\hline 90 & 1.65 & 273 & 69 & 31 & 18 & 11 \\
\hline 85 & 1.45 & 211 & 53 & 24 & 14 & 9 \\
\hline HI) & 1.3 & 169 & 43 & 19 & 11 & 7 \\
\hline 75 & 1.15 & 133 & 34 & 15 & 9 & 6 \\
\hline 70 & 1.05 & 111 & 28 & 13 & 7 & 5 \\
\hline 65 & 0.95 & 91 & 23 & 11 & 6 & 4 \\
\hline 60 & 0.85 & 73 & 19 & 9 & 5 & 3 \\
\hline 55 & 0.75 & 57 & 15 & 7 & 4 & 3 \\
\hline S0 & 0.7 & 49 & 13 & 6 & 4 & 2 \\
\hline
\end{tabular}

To arhieve a $90 \%$ confidence rating, + or $-5 \%$, a $\mathrm{minimum}$ of 273 responses is required for rtiiiilysis. The Stratified sampling technique is une I as the sampling technique in such a way th 1 stratum (sample) represents each demographic factor in the population

\subsection{Hypothesis}

- Tariff Kates and coverage cause churn from a network than QOS \& Technology of the operator in Sri Lankan Context.
- Influencing factors for churn are same for various subscriber segments

\subsection{Conceptual Model}

When Churn Management is concerned, it is necessary to identify what main factors affect the churn management process and those factors may vary based on whether it happens voluntary or involuntary.

Figure 3: Conceptual Model- Voluntary Churn

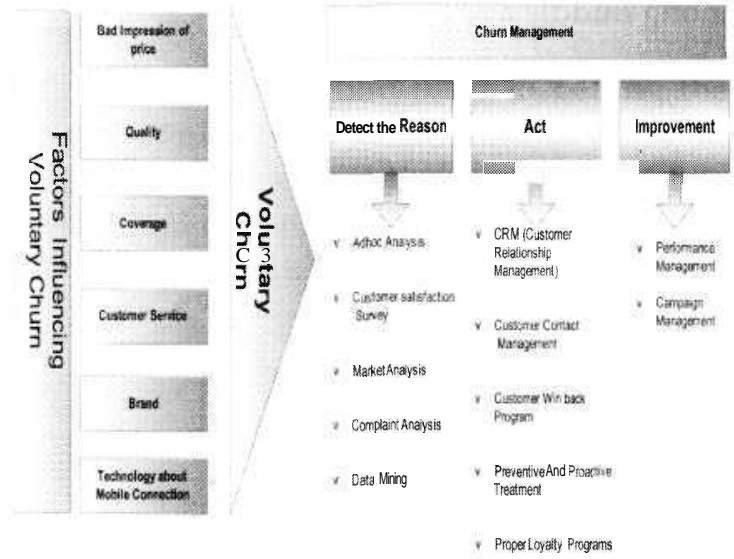

Figure 4: Conceptual Model

- Involuntary Churn

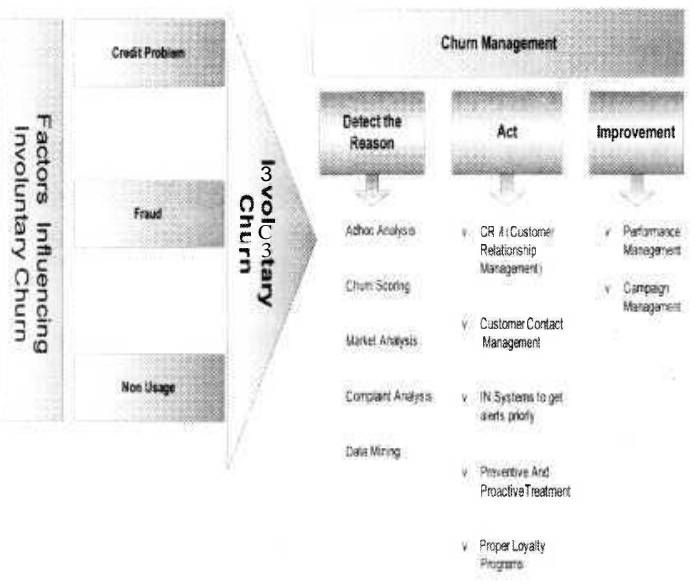

\section{Survey Results}

A Survey was conducted through a questionnaire that was printed both in Sinhala and English Medium. The Questionnaire was distributed both in soft and hard copies in such a way that it cover all demographic areas based on stratified sampling technique. SPSS, Minitab and Microsoft excel were used as software for data analysis. 
Table 3: Response Rate of Survey

\begin{tabular}{|l|c|c|c|}
\hline Medium & $\begin{array}{c}\text { No of } \\
\text { questions } \\
\text { distributed }\end{array}$ & $\begin{array}{c}\text { No of } \\
\text { response } \\
\text { received }\end{array}$ & $\begin{array}{c}\text { Response } \\
\text { Rate }\end{array}$ \\
\hline Sinhala & 225 & 158 & $70 \%$ \\
\hline English & 175 & 147 & $84 \%$ \\
\hline
\end{tabular}

When the distribution of Package type is concerned in the sample, Prepaid is more popular among younger generation. On the other hand Post paid Packages are more popular among middle age people.

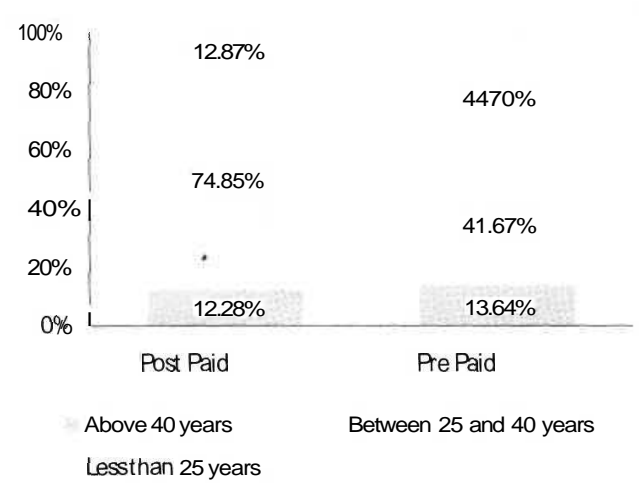

Figure 5: Age wise break down of Prepaid and Post paid customers

Apart from that, when Postpaid and Prepaid distribution are considered against the purpose for which they are used, most of the customers tend to go for a post paid package if they use the connection for their business activities as well.

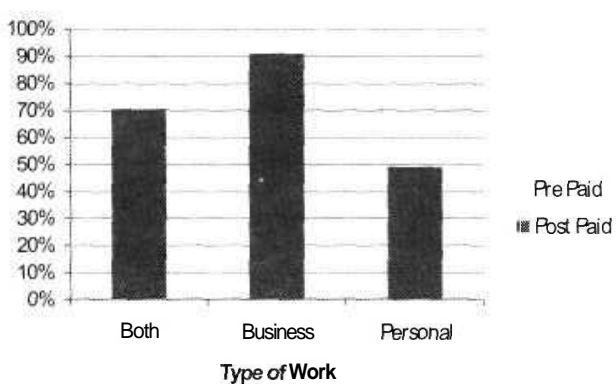

Figure 6: Package ty^. break down Vs type of work

As far as the distribution of average usage is concerned, majority of them are between Rs. 400 and Rs.1000 both in prepaid and postpaid. But when we compare the postpaid and prepaid distribution, the average usage of post paid customers is comparatively higher than the average usage of prepaid customers.

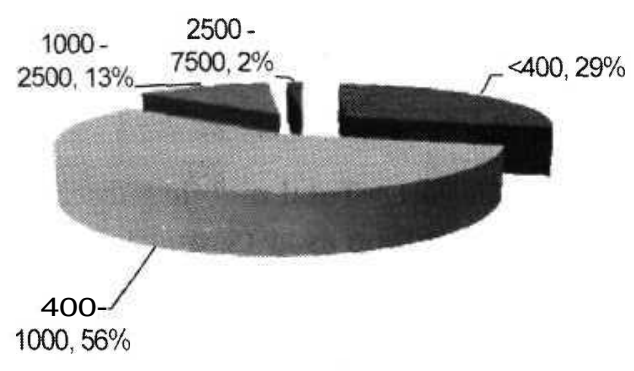

Figure 7: Average Monthly Usage - Prepaid

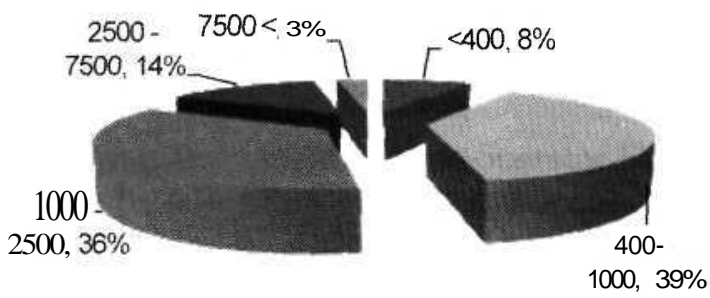

Figure 8: Average Monthly Usage - Post paid

More than $57 \%$ of customers say that mobile is important for their day to day activities. So we can say mobile has become an indispensable feature among the Sri Lankan mobile subscribers.

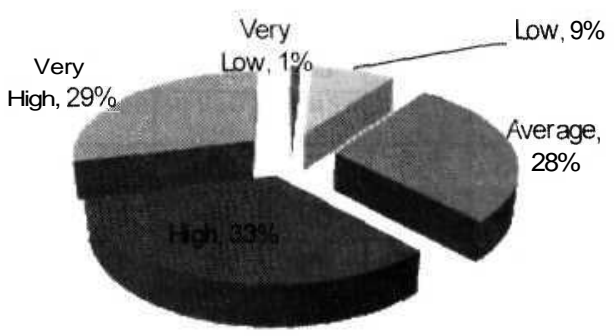

figure 9: Level of importancefor day to day activities

On the other hand, more than $52 \%$ of customers consider their mobile number as a unique identification for them. So if the mobile number portability is allowed in Sri Lankan context, there will be an impact on churn rate.

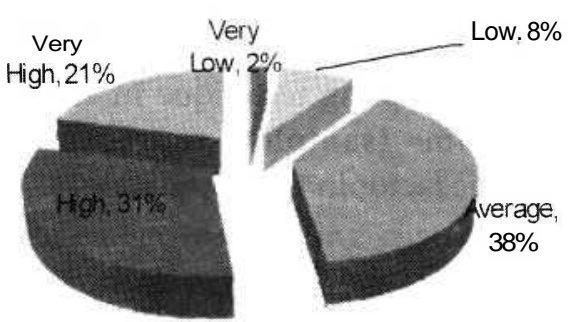

Figure 10: Level of importance of mobile number 
SMS is more popular among the younger generation so operators can offer special tariff for SMS when targeted to attract younger generation for a package.

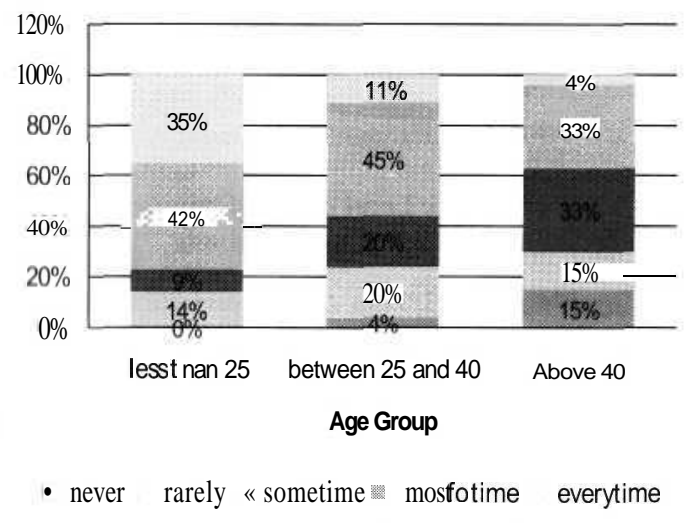

Figure 11: Variation of SMS usage with age

\section{Model Building}

The Binary Logistic regression technique is used In build a model to identify the impact of following parameters for the overall satisfaction.

Dependent Variable $=$ Overall Satisfaction of current Mobile Connection

In binary logistic regression model, since it is muled to have a binary value as the output variable, the value of overall satisfaction is converted in to binary values as follows.

\section{I able .1: Output value for Binary Logistic} regression model

\begin{tabular}{|l|c|c|}
\hline $\begin{array}{c}\text { Level of } \\
\text { satisfaction }\end{array}$ & Value & $\begin{array}{c}\text { Assigned value } \\
\text { after conversion }\end{array}$ \\
\hline Very Low & 1 & 0 - Dissatisfied \\
L.sw & 2 & 0 - Dissatisfied \\
Average & 3 & 0 - Dissatisfied \\
IIigh & 4 & 1 - Satisfied \\
Very High & 5 & 1 - Satisfied \\
\hline
\end{tabular}

\section{Input Parameters}

Statisfaction nl the current tariff

Satisfac tion of the coverage offered

Seri fiu tion of given information regarding the en rices

Sati lar tion nl given in formation regarding VAS fiervices

Based on results, if the customer is satisfied about the offered current tariff then there is a 42 times possibility of getting overall satisfaction about the service when compared with the situation when the customer highly dissatisfied with the current tariff. But when we consider the other parameters no significant relationship can be observed with the overall satisfaction of service

\section{Discussion of Findings}

\subsection{Possibility of Retaining the Customers without Churning}

Out of the 303 respondents, only 142 customers had a mobile connection prior to getting the present connection. From that a $60 \%$ of customers believe that the previous mobile operator had the opportunity to retain him/her in previous network.

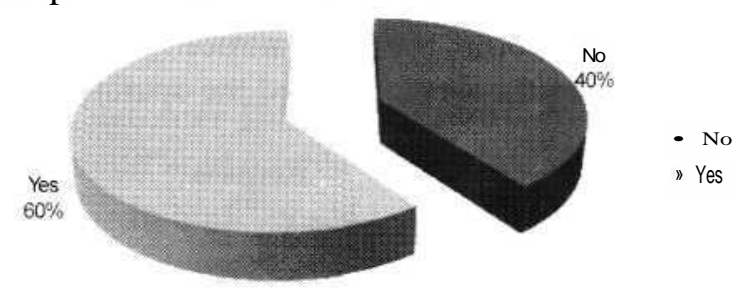

Figure 11: Ability to retain in the network

Based on the research out put, a major reason for churn is call charges $(41 \%)$, coverage $(32 \%)$ and the number of incoming free minutes (13\%).

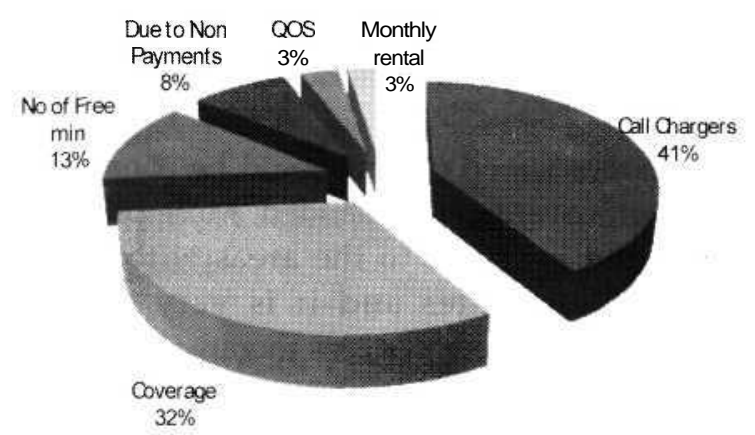

Figure 12: Reasonsfor chum

\subsection{Methods to Minimize Churn based on Customer Feed Back}

I. The into providing more benefits to long staying customers, it is necessary to enhance benefits to customers considering their network stay. But according to the survey results, only $57 \%$ of customers who have been with the same network for more than 3 years have incoming free connections. 


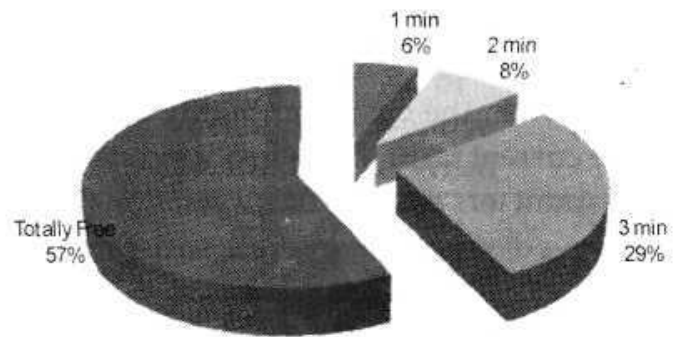

Figure 13: Incomingfree status of Long stay customers

II. Reasonable charges with out any hidden costs - Most of the time customers do not have a proper idea about the tariff of the package they are using. So it is necessary to make the customer aware of the charges applied for their mobile connection and it is better to provide a detailed bill without any additional cost. According to the survey results only about $50 \%$ of customers are satisfied about the information provided regarding the services offerd the operator.

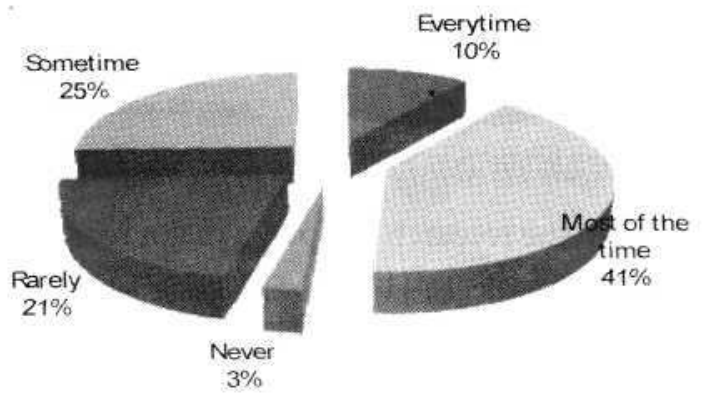

Figure 14: Level of satisfactionregarding information providedfor services

III. Customer feed backs should be considered when coverage is expanded. More priorities should be given to the areas with higher complaint rates and it is very vital to maintain proper systems to gather customer responses precisely.

IV. Customer Service officers should be more aware about the service and technology -

Customer Service officers and call center staff should be properly trained about the existing services. They should identify customer requirements properly and should be able to provide correct answers based on their requirements. Apart from that whenever a customer is contacted, it is better to select the most convenient language to contact the customer as otherwise inconvenience may be caused. Based on survey results of those who have made complaints, it appears that only $31 \%$

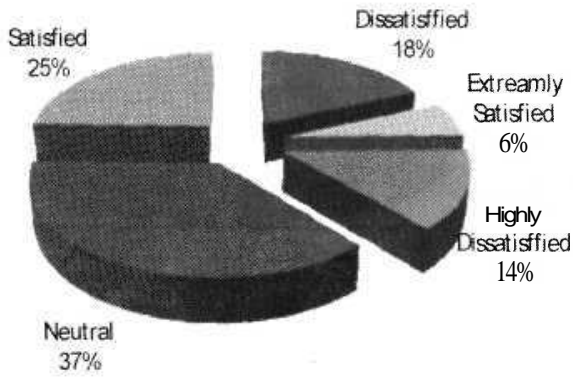

Figure 15: Level of satisfaction regarding complaint made

have been satisfied.

V. Give an opportunity to do payments in installments - When there is a huge outstanding bill and the customer does not have the ability to settle it due to genuine/ acceptable reasons, it is better to give a chance to the customer to settle the bill in installments. Currently this type of flexibility is offered by almost every Sri Lankan operator, but customers are not aware of it. This happens due to the existing gap between the customer and the operator.

VI. VAS against Churn - Value added services used by foreign mobile operators to strengthen stickiness between customer and operators, needs to be designed in such a way that they are important to customer's day to day life and helps them make life easier. According to the input received from the survey, about $61 \%$ of customers who do not use VAS services, say there is no importance for these day to day activities from the available VAS Services.

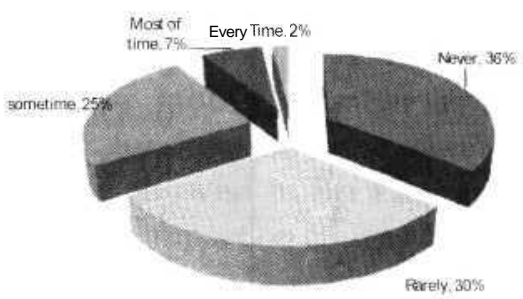

Figure 16: VAS usage

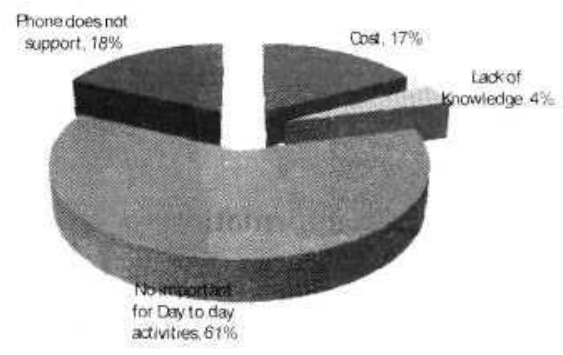

Figure 17: Reasons for low VAS Usage 
The Majority of Sri Lankan mobile users use their mobiles only for Voice and SMS. So it is a challenge to a mobile operator to design VAS services in such a way that it is aligned to customer requirements. On the other hand, it is necessary to make customers aware of the available value added services as most customers are not satisfied about information they receive from the operators about the VAS Bervices.

VII Loyalty Programs to Combat the Churn-In telecommunication environments, loyalty programs are required to retain the existing customer in the network. Operators can use parameters such as network stay, Average Usage and payment patterns to identify the most suitable segments for their loyalty programs. But in Sri Lankan environment loyalty program concept is new to the customers according to the survey results. This happens mainly because the benefits offered by operators are not visible to customers. Based on the survey results only $18 \%$ customers care about the loyalty points and $16 \%$ of customers do not have any idea about the loyalty schemes in mobile operators.

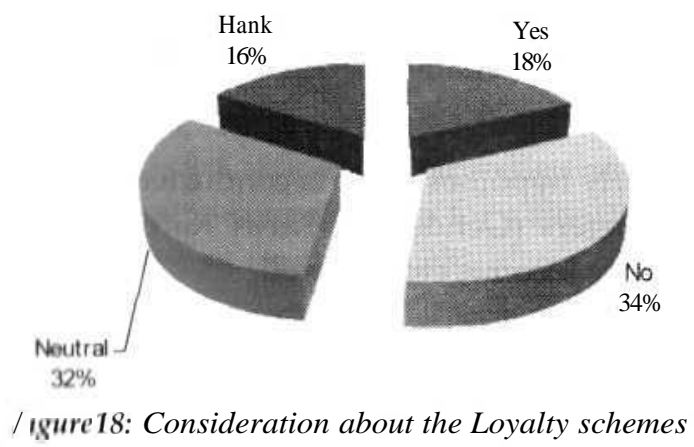

According to the survey results, this is basically happening due to lack of awareness on the loyalty points offerd operators. $36 \%$ of customers do not care about the loyalty points. But it mobile operators can offer free minutes, free SMSs or credit upgrades instead of loyalty points these schemes may be more effective as the Sri Lankan market is highly price sensitive.

\subsection{Methods to overcome Involuntary Churn}

In the Sri Lankan context, disconnections mainly happen due to involuntary churn. Most of them are post paid customers, basically due to non payments. Based on the input received from the post paid customers in the sample, $35 \%$ of them have been disconnected at least once although still they remain in the network. To overcome involuntary churn rate, post paid customers should be aware about the offered credit limit, and need to be aligned loyalty point schemes to paymasters.

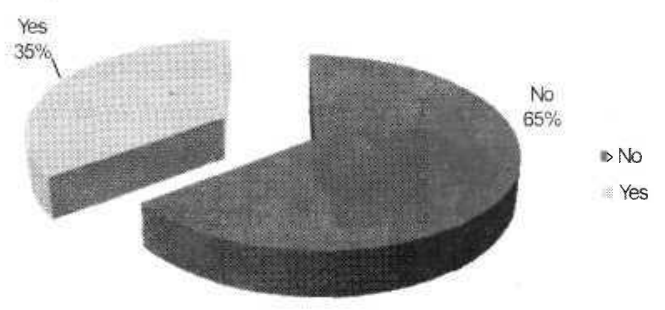

Figure 19: Disconnections happened due to credit limit exceed

Based on customer's inputs, suggestions to reduce involuntary churn

- Customer should be informed about the credit limit offered

- Credit limit should be increased considering Bill amounts, payment pattern and Network Stay

- It is Better to inform the customer through a telephone call before disconnecting

- Disconnecting process should not run on holidays/Weekends

- Payment outlets should be increased

- Give more concessions for payments based on past records

- Time gap between outgoing barred and temporary disconnections should be increased

\section{Hypothesis Testing}

I. Tariff Rates and coverage effect for churn from a network than QOS \& Technology of the operator in Sri Lankan Context.

Consideration about the tariff rates $=$ (Consideration about the No of Incoming free minutes + Consideration about Monthly rental + Consideration about Call Charges) / 3

Variation of Tariff and QOS can be clearly observed through figure 21 . 


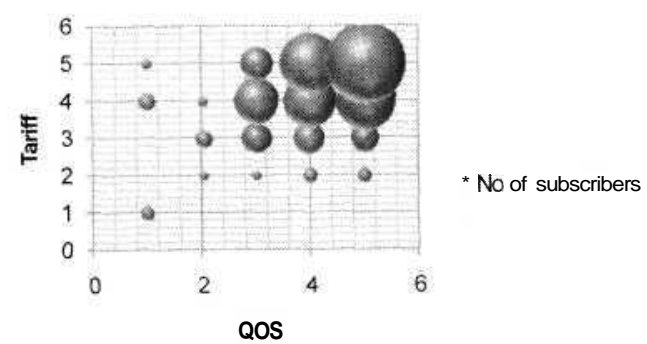

Figure 20: Level of impact of influence factors for Chum - Tariffs QOS

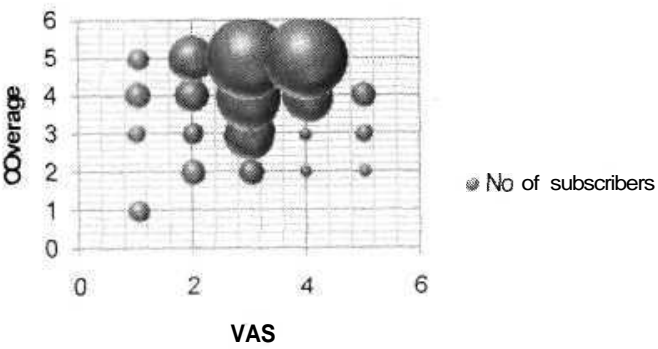

Figure 21: Level of impact of influencefactors for Chum - Coverage Vs VAS

In both graphs (figure 20 and figure 21) we can clearly observe, bubbles are scattered towards higher values in tariff and coverage with respect to QOS and VAS respectively. From that we can say Tariff Rates and coverage effect churn from a network than QOS \& Technology of the operator in Sri Lankan Context

II. Influencing factors for churn (Tariff, VAS, QOS and Coverage) are same for various subscriber segments(Different Age groups, Educational levels, Income Levels and Gender )

$\mathrm{H}_{01}$ - There is no relationship between the consideration of tariff rates and Age (Tariff rates and Age are independent parameters)

$\mathrm{H}_{\mathrm{a} 1}$ - There is a relationship between the consideration of tariff rates and Age (Tariff rates and Age are not independent parameters)
Rows: Age Columns: Tariff

\begin{tabular}{|l|l|l|l|l|}
\hline & 1 & 2 & 3 & All \\
\hline 1 & 10 & 18 & 53 & 81 \\
& 14.12 & 8.79 & 58.09 & 81.00 \\
& -4.122 & 9.207 & -5.086 & $*$ \\
\multirow{4}{*}{2} & -1.0968 & 3.1050 & -0.6673 & $*$ \\
& 33 & 10 & 141 & 184 \\
& 32.08 & 19.97 & 131.95 & 184.00 \\
& 0.921 & -9.974 & 9.053 & $*$ \\
& 0.1626 & -2.2317 & 0.7881 & $*$ \\
3 & 10 & 5 & 24 & 39 \\
& 6.80 & 4.23 & 27.97 & 39.00 \\
& 3.201 & 0.766 & -3.967 & $*$ \\
& 1.2275 & 0.3725 & -0.7502 & $*$ \\
& 53 & 33 & 218 & 304 \\
& 53.00 & 33.00 & 218.00 & 304.00 \\
& $*$ & $*$ & $*$ & $*$ \\
& $*$ & $*$ & $*$ & \\
\hline
\end{tabular}

Pearson Chi-Square $=19.125, \mathrm{DF}=4, \mathrm{P}-$ Value $=$ 0.001

Likelihood Ratio Chi-Square $=17.958, \mathrm{DF}=4, \mathrm{P}$ Value $=0.001$

As confidence level is $90 \%$ and $\mathrm{P}$ value received $<0.1$

Reject the H01. So we can say the consideration of tariff rates and Age are dependent parameters.

Similarly hypothesis test is conducted for other parameters (Gender Vs Tariff Rates, Age Vs Monthly Income, etc..) as well.

\section{Conclusion}

Due to profound competition, controlling churn rate has become a challenge to Sri Lankan Mobile Operators. In this regard it is of paramount importance that the operators manage churn, as without proper churn management strategies, they will not be able to retain the market share. The main reasons for churn were identified after analyzing customer expectations and behavior patterns through this research.

Based on the research outcome, it can be stated that Sri Lankan subscribers are highly price sensitive and that the majority of customers who have churned from one network to another is due to lower tariff rates offered by the latter. 
Further, it was identified that features for different packages are not being properly directed to the target audience or a segment. Therefore it is necessary to build new products or Packages after cautious analysis of interests of different segments.

e.g.: As most of the younger people prefer to use SMS, special packages can be introduced with low tariff for SMS.

It is also vital to give more benefits to existing customers considering their network stay.

e.g.: Number of incoming free minutes can be increased considering the number of years in the network.

On the other hand, the majority of mobile subscribers use value added services very rarely. It is a big challenge to Sri Lankan mobile operators to align their value added services with culture, attitudes and values of Sri Lankan people. But, however, they should educate customers about the available value added services and they must use different strategies to promote existing value added services.

Meanwhile, it is necessary to align all discounts, loyalty programs, promotions with financial benefits to customers. Otherwise it is difficult to attract attention of customers due to the nature of the Sri Lankan market.

E.g: if customer recharges the card with a Rs.1000 card, if operator can assign bonus Rs. 200 , customer tends to go for a Rs. 1000 card as there is an explicit benefit.

From the operators' point of view, they need to provide special attention to most profitable customers; since if they can retain them the impact of churn can be minimized. As most disconnections are caused by non payment, it is necessary to give special discounts to paymasters to encourage timely payments.

Finally if proper churn management policies are available in the Sri Lankan mobile market it will help increase the customer satisfaction while minimizing losses incurred by mobile operators due to bad debts, and acquisition costs.

\section{Limitations of the Study}

There were some limitations experienced in achieving the objective of this research project.

I. Difficulty in collecting accurate information (e.g.: Churn Rate, Bad debts per month, current strategies to minimize the churn) as competitive information is not exposed to a third party.

II. Non availability of comprehensive literature on this topic both in Sri Lankan and Asian region contexts

III. Some customers are not familiar with words/concepts in the questionnaire (E .g : Credit limit, Loyalty points ) to give more detailed answers

IV. Although relevant research papers are available on the Internet, it is necessary to pay for reading their full content.

V. Lack of empirical evidence to support some gathered information.

VI. Non availability of statistics to do a proper stratified sampling in such a way that stratum represents the population

\section{References}

1. Telecommunications Regulatory Commission of Sri Lanka, "Subscriber Data Analysis", Telecommunication Regulatory Commission, [Online]. Available: http://www.trc.gov.lk/ stat_analysis.htm [Accessed Jul 15, 2007].

2. "The path towards mobile customer loyalty in Asia Pacific," Frost \& Sullivan, pp.3-12, 2007

3. R. Mattison, Telecom Churn Management, Fuquay-Varina: ADPG, 2001, pp. 41 - 45

4. S.M.Keavency, M.Parthasarathy, "Customer switching Behavior in online services", Journal of the academy of marketing science, volume $29, \mathrm{No}$ 4,pp374-390

5. C.Gepper, "Customer Churn Management", KPMG International, a Swiss Association, pp 1- 6, 2002

6. M.L .Agrawal, "Customer Relationship Managemnt \& Corporate Renaissance," Journal of Services research, Vol. 3,No 2,pp 68-73,Oct 2003

7. M.C .Mozer, R .Wolniewicz., "Predicting subscriber dissatisfaction and improving retention in the wireless telecommunications industry", IEEE Transactions, vol .11, pp 690-696, 2000. 